Research Article

\title{
On Solvability Theorems of Second-Order Ordinary Differential Equations with Delay
}

\author{
Nai-Sher Yeh \\ Department of Mathematics, Fu Jen Catholic University, Xinzhuang District, New Taipei City 24205, Taiwan \\ Correspondence should be addressed to Nai-Sher Yeh; 038300@mail.fju.edu.tw
}

Received 24 October 2017; Accepted 28 January 2018; Published 1 April 2018

Academic Editor: Chun-Lei Tang

Copyright (C) 2018 Nai-Sher Yeh. This is an open access article distributed under the Creative Commons Attribution License, which permits unrestricted use, distribution, and reproduction in any medium, provided the original work is properly cited.

For each $x_{0} \in[0,2 \pi)$ and $k \in \mathbf{N}$, we obtain some existence theorems of periodic solutions to the two-point boundary value problem $u^{\prime \prime}(x)+k^{2} u\left(x-x_{0}\right)+g\left(x, u\left(x-x_{0}\right)\right)=h(x)$ in $(0,2 \pi)$ with $u(0)-u(2 \pi)=u^{\prime}(0)-u^{\prime}(2 \pi)=0$ when $g:(0,2 \pi) \times \mathbf{R} \rightarrow \mathbf{R}$ is a Caratheodory function which grows linearly in $u$ as $|u| \rightarrow \infty$, and $h \in L^{1}(0,2 \pi)$ may satisfy a generalized LandesmanLazer condition $(1+\operatorname{sign}(\beta)) \int_{0}^{2 \pi} h(x) v(x) d x<\int_{v(x)>0} g_{\beta}^{+}(x)|v(x)|^{1-\beta} d x+\int_{v(x)<0} g_{\beta}^{-}(x)|v(x)|^{1-\beta} d x$ for all $v \in N(L) \backslash\{0\}$. Here $N(L)$ denotes the subspace of $L^{1}(0,2 \pi)$ spanned by $\sin k x$ and $\cos k x,-1<\beta \leq 0, g_{\beta}^{+}(x)=\liminf _{u \rightarrow \infty}\left(g(x, u) u /|u|^{1-\beta}\right)$, and $g_{\beta}^{-}(x)=$ $\liminf _{u \rightarrow-\infty}\left(g(x, u) u /|u|^{1-\beta}\right)$.

\section{Introduction}

Let $x_{0} \in[0,2 \pi)$ and $k \in \mathbf{N}$ be fixed. We consider the following two-point boundary value problems:

$$
\begin{aligned}
& u^{\prime \prime}(x)+k^{2} u\left(x-x_{0}\right)+g\left(x, u\left(x-x_{0}\right)\right)=h(x) \\
& \text { in }(0,2 \pi), \\
& u(0)-u(2 \pi)=u^{\prime}(0)-u^{\prime}(2 \pi)=0, \\
& u^{\prime \prime}(x)+k^{2} u(x)-g\left(x, u\left(x-x_{0}\right)\right)=-h(x) \\
& u(0)-u(2 \pi)=u^{\prime}(0)-u^{\prime}(2 \pi)=0,
\end{aligned}
$$

where $h \in L^{1}(0,2 \pi)$ is given and $g:(0,2 \pi) \times \mathbf{R} \rightarrow \mathbf{R}$ is a Caratheodory function; that is, $g(x, u)$ is continuous in $u \in$ $\mathbf{R}$, for a.e. $x \in(0,2 \pi)$, is measurable in $x \in(0,2 \pi)$ for all $u \in \mathbf{R}$, and satisfies, for each $r>0$, the fact that there exists an $a_{r} \in L^{1}(0,2 \pi)$ such that

$$
|g(x, u)| \leq a_{r}(x)
$$

for a.e. $x \in(0,2 \pi)$ and all $|u| \leq r$. Concerning the growth condition of the nonlinear term $g$ to (1) and (2), we assume that
(H) there exist constants $-1<\beta \leq 0, r_{0}>0$, and $a, b, c, d \in L^{1}(0,2 \pi), a, b \geq 0$ and $a(x) \leq 2 k+1$ for a.e. $x \in(0,2 \pi)$ with strict inequality on a positive measurable subset of $(0,2 \pi)$, such that for a.e. $x \in$ $(0,2 \pi)$ and all $u \geq r_{0}$

$$
c(x)|u|^{-\beta} \leq g(x, u) \leq a(x)|u|+b(x) ;
$$

and for a.e. $x \in(0,2 \pi)$ and all $u \leq-r_{0}$

$$
-a(x)|u|-b(x) \leq g(x, u) \leq d(x)|u|^{-\beta} ;
$$

(G) there exist constants $-1<\beta \leq 0, r_{0}>0$, and $a, b, c, d \in L^{1}(0,2 \pi), a, b \geq 0$ and $a(x) \leq 2 k-1$ for a.e. $x \in(0,2 \pi)$ with strict inequality on a positive measurable subset of $(0,2 \pi)$, such that for a.e. $x \in$ $(0,2 \pi)$ and all $u \geq r_{0}$

$$
c(x)|u|^{-\beta} \leq g(x, u) \leq a(x)|u|+b(x) ;
$$

and for a.e. $x \in(0,2 \pi)$ and all $u \leq-r_{0}$

$$
-a(x)|u|-b(x) \leq g(x, u) \leq d(x)|u|^{-\beta}
$$


respectively, and a generalized Landesman-Lazer condition

$$
\begin{aligned}
0< & \int_{v(x)>0} g_{\beta}^{+}(x)|v(x)|^{1-\beta} d x \\
& +\int_{v(x)<0} g_{\beta}^{-}(x)|v(x)|^{1-\beta} d x,
\end{aligned}
$$

for all $v \in N(L) \backslash\{0\}$, may be satisfied. Here $N(L)$ denotes the subspace of $L^{1}(0,2 \pi)$ spanned by $\sin k x$ and $\cos k x$, $\beta \in \mathbf{R}, g_{\beta}^{+}(x)=\liminf _{u \rightarrow \infty}\left(g(x, u) u /|u|^{1-\beta}\right)$, and $g_{\beta}^{-}(x)=$ $\liminf \operatorname{si-\infty }_{u \rightarrow}\left(g(x, u) u /|u|^{1-\beta}\right)$. Under assumptions and either with or without the Landesman-Lazer condition

$$
\begin{aligned}
\int_{0}^{2 \pi} h(x) v(x) d x< & \int_{v(x)>0} g_{0}^{+}|v(x)| d x \\
& +\int_{v(x)<0} g_{0}^{-}|v(x)| d x
\end{aligned}
$$

for all $v \in N(L) \backslash\{0\}$, the solvability of the problem (1) has been extensively studied if the nonlinearity $g(x, u)$ has at most linear growth in $u$ as $|u| \rightarrow \infty$ (see [1-13] for the case $x_{0}=0$ and [14-16] for the general case) or grows superlinearly in $u$ in one of directions $u \rightarrow \infty$ and $u \rightarrow-\infty$ and may be bounded in the other (see $[8,17]$ for the case $x_{0}=0$ and [14] for the general case when $k=0$ ). Based on the well-known Leray-Schauder continuation method (see $[18,19])$, we obtain solvability theorems to (1) (resp., (2)) when $g(x, u)$ satisfies $(H)$ (resp., $(G)$ ) and either (8) with $-1<\beta<0$ or (9) with $\beta=0$ is satisfied, which extends the results of [15] for the nonresonance case, and has been established in [9] for the case $x_{0}=0$ and $g(x, u)$ grows sublinearly in $u$ as $|u| \rightarrow \infty$ with $-1<\beta \leq 1$. Unfortunately, it is still unknown when $k \in \mathbf{N}, g(x, u)$ grows linearly in $u$ as $|u| \rightarrow \infty$ and the assumption of (8) is replaced by

$$
\begin{aligned}
\int_{0}^{2 \pi} h(x) v(x) d x & =0 \\
& <\int_{v(x)>0} g_{\beta}^{+}(x)|v(x)|^{1-\beta} d x \\
& +\int_{v(x)<0} g_{\beta}^{-}(x)|v(x)|^{1-\beta} d x
\end{aligned}
$$

for all $v \in N(L) \backslash\{0\}$ with $\beta>0$. In the following we will make use of real Banach spaces $L^{p}(0,2 \pi), C[0,2 \pi]$ and Sobolev spaces $W^{2,1}(0,2 \pi)$ and $H^{1}(0,2 \pi)$. The norms of $L^{p}(0,2 \pi), C[0,2 \pi]$ and $H^{1}(0,2 \pi)$ are denoted by $\|u\|_{L^{p}},\|u\|_{C}$ and $\|u\|_{H^{1}}$, respectively. By a solution of (1), we mean a periodic function $u: \mathbf{R} \rightarrow \mathbf{R}$ of period $2 \pi$ which belongs to $W^{2,1}(0,2 \pi)$ and satisfies the differential equation in (1) a.e. $x \in(0,2 \pi)$.

\section{Existence Theorems}

For each $v \in W^{2,1}(0,2 \pi)$ with $v(0)-v(2 \pi)=v^{\prime}(0)-v^{\prime}(2 \pi)=$ 0 and $k \in \mathbf{N}$, we write $\bar{v}=\sum_{0 \leq j \leq k} P_{j} v, \widetilde{v}=\sum_{j>k} P_{j} v$, and $v^{\perp}=\sum_{0 \leq j \neq k} P_{j} v$. Here $P_{j} v$ denotes the projection of $v$ on the eigenspace of $d^{2} / d x^{2}$ spanned by $\sin j x$ and cos $j x$ for $j \in \mathbf{N} \cup$ $\{0\}$. Just as an application of [11, Lemma 2] or [1, Lemma 2.2], we can modify slightly the proof of [15, Lemma 1] to obtain the next lemma.

Lemma 1. Let $k \in \mathbf{N} \cup\{0\}$ and $\Gamma$ be a nonnegative $L^{1}(0,2 \pi)$ function such that for a.e. $x \in(0,2 \pi), \Gamma(x) \leq 2 k+1$ with strict inequality on a positive measurable subset of $(0,2 \pi)$. Then there exists a constant $K_{1}>0$ such that

$$
\begin{aligned}
& \int_{0}^{2 \pi}\left(\bar{u}\left(x-x_{0}\right)-\tilde{u}(x)\right) \\
& \cdot\left(u^{\prime \prime}(x)+k^{2} u\left(x-x_{0}\right)+p(x) u\left(x-x_{0}\right)\right) d x \\
& \quad \geq K_{1}\left\|u^{\perp}\right\|_{H^{1}}^{2}
\end{aligned}
$$

whenever $p \in L^{1}(0,2 \pi)$ with $0 \leq p(x) \leq \Gamma(x)$ for a.e. $x \in$ $(0,2 \pi)$ and $u \in W^{2,1}(0,2 \pi)$ is a periodic function of period $2 \pi$ with $u(0)-u(2 \pi)=u^{\prime}(0)-u^{\prime}(2 \pi)=0$.

Proof. Just as in [20, Lemma 1], we can modify slightly the proof of [11, Lemma 2] or [1, Lemma 2.2] to obtain the fact that there exists a constant $K_{1}>0$ such that

$$
\begin{aligned}
\int_{0}^{2 \pi} & \left(\tilde{u}^{\prime}(x)\right)^{2}-\left(k^{2}+p(x)\right)(\tilde{u}(x))^{2} d x \\
& +\int_{0}^{2 \pi}\left(k^{2}+p(x)\right)(\bar{u}(x))^{2}-\left(\bar{u}^{\prime}(x)\right)^{2} d x \\
\geq & 2 K_{1}\left\|u^{\perp}\right\|_{H^{1}}^{2}
\end{aligned}
$$

whenever $p \in L^{1}(0,2 \pi)$ with $0 \leq p(x) \leq \Gamma(x)$ for a.e. $x \in(0,2 \pi)$ and $u \in W^{2,1}(0,2 \pi)$ with $u(0)-u(2 \pi)=u^{\prime}(0)-$ $u^{\prime}(2 \pi)=0$. Let us extend $u(x)$ and $p(x) 2 \pi$ periodically in $x$ to all of $\mathbf{R}$ and then use the same notations for the periodic extensions as for the original functions. In this case, we have $\int_{0}^{2 \pi}\left(\tilde{u}^{\prime}(x)\right)^{2} d x=\int_{0}^{2 \pi}\left(\tilde{u}^{\prime}\left(x-x_{0}\right)\right)^{2} d x$ and

$$
\begin{aligned}
& \int_{0}^{2 \pi}\left[u^{\prime \prime}(x)+\left(k^{2}+p(x)\right) u\left(x-x_{0}\right)\right] \\
& \cdot\left(\bar{u}\left(x-x_{0}\right)-\tilde{u}(x)\right) d x=\int_{0}^{2 \pi}\left(\tilde{u}^{\prime}(x)\right)^{2} d x \\
& -\int_{0}^{2 \pi} \bar{u}^{\prime}(x) \bar{u}^{\prime}\left(x-x_{0}\right) d x+\frac{1}{2} \int_{0}^{2 \pi}\left(k^{2}+p(x)\right) \\
& \cdot\left[\left(\bar{u}\left(x-x_{0}\right)\right)^{2}-(\tilde{u}(x))^{2}-\left(\tilde{u}\left(x-x_{0}\right)\right)^{2}\right] d x \\
& +\frac{1}{2} \int_{0}^{2 \pi}\left(k^{2}+p(x)\right) \\
& \cdot\left[\bar{u}\left(x-x_{0}\right)+\tilde{u}\left(x-x_{0}\right)-\tilde{u}(x)\right]^{2} d x
\end{aligned}
$$




$$
\begin{aligned}
& \geq \int_{0}^{2 \pi}\left(\tilde{u}^{\prime}(x)\right)^{2} d x-\frac{1}{2} \int_{0}^{2 \pi}\left(\bar{u}^{\prime}(x)\right)^{2} \\
& +\left(\bar{u}^{\prime}\left(x-x_{0}\right)\right)^{2} d x+\frac{1}{2} \int_{0}^{2 \pi}\left(k^{2}+p(x)\right) \\
& \cdot\left[\left(\bar{u}\left(x-x_{0}\right)\right)^{2}-(\widetilde{u}(x))^{2}-\left(\widetilde{u}\left(x-x_{0}\right)\right)^{2}\right] d x \\
& +\frac{1}{2} \int_{0}^{2 \pi}\left(k^{2}+p(x)\right) \\
& \cdot\left[\bar{u}\left(x-x_{0}\right)+\widetilde{u}\left(x-x_{0}\right)-\widetilde{u}(x)\right]^{2} d x \geq \frac{1}{2} \\
& \cdot \int_{0}^{2 \pi}\left(\tilde{u}^{\prime}(x)\right)^{2} \\
& -\left(k^{2}+p(x)\right)(\widetilde{u}(x))^{2} d x+\frac{1}{2} \\
& \cdot \int_{0}^{2 \pi}\left(\tilde{u}^{\prime}\left(x-x_{0}\right)\right)^{2}-\left(k^{2}+p(x)\right) \\
& \cdot\left(\tilde{u}\left(x-x_{0}\right)\right)^{2} d x+\frac{1}{2} \int_{0}^{2 \pi}\left(k^{2}+p(x)\right) \\
& \cdot\left(\bar{u}\left(x-x_{0}\right)\right)^{2}-\left(\bar{u}^{\prime}\left(x-x_{0}\right)\right)^{2} d x-\frac{1}{2} \\
& \cdot \int_{0}^{2 \pi}\left(\bar{u}^{\prime}(x)\right)^{2} d x+\frac{1}{2} \int_{0}^{2 \pi}\left(k^{2}+p(x)\right) \\
& \cdot\left[\bar{u}\left(x-x_{0}\right)+\widetilde{u}\left(x-x_{0}\right)-\widetilde{u}(x)\right]^{2} d x \text {. }
\end{aligned}
$$

Since $\int_{0}^{2 \pi}(\bar{u}(x))^{2} d x=\int_{0}^{2 \pi}\left(\bar{u}\left(x-x_{0}\right)\right)^{2} d x, p(x) \geq 0$ for a.e. $x \in$ $(0,2 \pi)$, and $\int_{0}^{2 \pi} \bar{v}(x) \widetilde{w}(x)=0$ for all $v, w \in W^{2,1}(0,2 \pi)$ with $v(0)-v(2 \pi)=v^{\prime}(0)-v^{\prime}(2 \pi)=0$ and $w(0)-w(2 \pi)=w^{\prime}(0)-$ $w^{\prime}(2 \pi)=0$, we have $\int_{0}^{2 \pi}\left(\widetilde{u}^{\prime}(x)\right)^{2}-\left(k^{2}+p(x)\right)(\widetilde{u}(x))^{2} d x \geq 0$ and

$$
\begin{aligned}
& -\frac{1}{2} \int_{0}^{2 \pi}\left(\bar{u}^{\prime}(x)\right)^{2} d x+\frac{1}{2} \int_{0}^{2 \pi}\left(k^{2}+p(x)\right) \\
& \cdot\left[\bar{u}\left(x-x_{0}\right)+\tilde{u}\left(x-x_{0}\right)-\tilde{u}(x)\right]^{2} d x \geq-\frac{1}{2} \\
& \cdot \int_{0}^{2 \pi}\left(\bar{u}^{\prime}(x)\right)^{2} d x+\frac{1}{2} \\
& \cdot \int_{0}^{2 \pi} k^{2}\left[\bar{u}\left(x-x_{0}\right)+\widetilde{u}\left(x-x_{0}\right)-\tilde{u}(x)\right]^{2} d x \\
& =\frac{1}{2}\left[-\int_{0}^{2 \pi}\left(\bar{u}^{\prime}(x)\right)^{2} d x\right. \\
& \left.+k^{2} \int_{0}^{2 \pi}\left(\bar{u}\left(x-x_{0}\right)\right)^{2} d x\right]+\frac{1}{2} \\
& \cdot k^{2} \int_{0}^{2 \pi}\left[\widetilde{u}\left(x-x_{0}\right)-\widetilde{u}(x)\right]^{2} d x \geq 0 .
\end{aligned}
$$

Combining (12) with (13), we have

$$
\begin{aligned}
& \int_{0}^{2 \pi}\left(\bar{u}\left(x-x_{0}\right)-\tilde{u}(x)\right) \\
& \cdot\left(u^{\prime \prime}(x)+k^{2} u\left(x-x_{0}\right)+p(x) u\left(x-x_{0}\right)\right) d x \\
& \quad \geq \frac{1}{2} \int_{0}^{2 \pi}\left(\tilde{u}^{\prime}\left(x-x_{0}\right)\right)^{2}-\left(k^{2}+p(x)\right) \\
& \cdot\left(\tilde{u}\left(x-x_{0}\right)\right)^{2} d x+\frac{1}{2} \int_{0}^{2 \pi}\left(k^{2}+p(x)\right) \\
& \cdot\left(\bar{u}\left(x-x_{0}\right)\right)^{2}-\left(\bar{u}^{\prime}\left(x-x_{0}\right)\right)^{2} d x \\
& \geq K_{1}\left\|u^{\perp}\right\|_{H^{1}\left(x_{0}, x_{0}+2 \pi\right)}^{2}=K_{1}\left\|u^{\perp}\right\|_{H^{1}}^{2} .
\end{aligned}
$$

Lemma 2. Let $k \in \mathbf{N}$ and $\Gamma$ be a nonnegative $L^{1}(0,2 \pi)$ function such that for a.e. $x \in(0,2 \pi), \Gamma(x) \leq 2 k-1$ with strict inequality on a positive measurable subset of $(0,2 \pi)$. Then there exists a constant $K_{2}>0$ such that

$$
\begin{aligned}
& \int_{0}^{2 \pi}\left(\overline{\bar{u}}\left(x-x_{0}\right)-\tilde{\widetilde{u}}(x)\right) \\
& \cdot\left(u^{\prime \prime}(x)+k^{2} u(x)-p(x) u\left(x-x_{0}\right)\right) d x \\
& \quad \geq K_{2}\left\|u^{\perp}\right\|_{H^{1}}^{2}
\end{aligned}
$$

whenever $p \in L^{1}(0,2 \pi)$ with $0 \leq p(x) \leq \Gamma(x)$ for a.e. $x \in$ $(0,2 \pi)$ and $u \in W^{2,1}(0,2 \pi)$ is a periodic function of period $2 \pi$ with $u(0)-u(2 \pi)=u^{\prime}(0)-u^{\prime}(2 \pi)=0$. Here $\overline{\bar{v}}=\sum_{0 \leq j<k} P_{j} v$ and $\widetilde{\widetilde{v}}=\sum_{j \geq k} P_{j} v$ for each $v \in W^{2,1}(0,2 \pi)$ with $v(0)-v(2 \pi)=$ $v^{\prime}(0)-v^{\prime}(2 \pi)=0$.

Theorem 3. Let $k \in \mathbf{N} \cup\{0\}$ and $g:(0,2 \pi) \times \mathbf{R} \rightarrow \mathbf{R}$ be a Caratheodory function satisfying $(H)$. Then for each $h \in$ $L^{1}(0,2 \pi)$ problem (1) has a solution $u$, provided that either (8) with $-1<\beta<0$ or (9) with $\beta=0$ holds.

Proof. Let $\alpha \in \mathbf{R}$ be fixed and $0<\alpha<2 k+1$. We consider the boundary value problems

$$
\begin{aligned}
& u^{\prime \prime}(x)+k^{2} u\left(x-x_{0}\right)+(1-t) \alpha u\left(x-x_{0}\right) \\
& \quad+\operatorname{tg}\left(x, u\left(x-x_{0}\right)\right)=\operatorname{th}(x) \text { in }(0,2 \pi), \\
& u(0)-u(2 \pi)=u^{\prime}(0)-u^{\prime}(2 \pi)=0
\end{aligned}
$$

for $0 \leq t \leq 1$, which becomes the original problem when $t=1$. Since $0<\alpha<2 k+1$, we observe from Lemma 1 that (17) has only a trivial solution when $t=0$. To apply the Leray-Schauder continuation method, it suffices to show that solutions to (17) for $0<t<1$ have an a priori bound in $H^{1}(0,2 \pi)$. To this end, let $\theta: \mathbf{R} \rightarrow \mathbf{R}$ be a continuous function 
such that $0 \leq \theta \leq 1, \theta(u)=0$ for $|u| \leq r_{0}$, and $\theta(u)=1$ for $|u| \geq 2 r_{0}$. We define $e(x)=\max \left\{a_{r_{0}}(x), b(x),|c(x)|,|d(x)|\right\}$,

$$
\begin{aligned}
& g_{1}(x, u) \\
& = \begin{cases}\min \left\{g(x, u)+e(x)|u|^{-\beta}, a(x) u\right\} \theta(u) & \text { if } u \geq 0 \\
\max \left\{g(x, u)-e(x)|u|^{-\beta}, a(x) u\right\} \theta(u) & \text { if } u \leq 0,\end{cases}
\end{aligned}
$$

and $g_{2}(x, u)=g(x, u)-g_{1}(x, u)$. Then $g_{1}, g_{2}:(0,2 \pi) \times \mathbf{R} \rightarrow$ $\mathbf{R}$ are Caratheodory functions, such that for a.e. $x \in(0,2 \pi)$ and $u \in \mathbf{R}, u \neq 0$

$$
\begin{array}{r}
0 \leq \frac{g_{1}(x, u)}{u} \leq a(x), \\
\left|g_{2}(x, u)\right| \leq e(x)|u|^{-\beta}+e(x) .
\end{array}
$$

If $u$ is a possible solution to (17) for some $0<t<1$, then using (19), (20), and Lemma 1, we have

$$
\begin{aligned}
0= & \int_{0}^{2 \pi}\left(\bar{u}(x)-\tilde{u}\left(x-x_{0}\right)\right)\left[u^{\prime \prime}(x)+k^{2} u\left(x-x_{0}\right)\right. \\
& +(1-t) \alpha u\left(x-x_{0}\right)+\operatorname{tg}_{1}\left(x, u\left(x-x_{0}\right)\right) \\
& \left.+\operatorname{tg}_{2}\left(x, u\left(x-x_{0}\right)\right)-\operatorname{th}(x)\right] d x \\
& \geq K_{1}\left\|u^{\perp}\right\|_{H^{1}}^{2}-\left(\|e\|_{L^{1}}\|u\|_{C}^{-\beta}+\|e\|_{L^{1}}+\|h\|_{L^{1}}\right)\left(\|\bar{u}\|_{C}\right. \\
& \left.+\|\tilde{u}\|_{C}\right) \geq K_{1}\left\|u^{\perp}\right\|_{H^{1}}^{2}-C_{1}\left(\|u\|_{C}^{-\beta}+1\right)\left(\|\bar{u}\|_{H^{1}}\right. \\
& \left.+\|\tilde{u}\|_{H^{1}}\right),
\end{aligned}
$$

which implies that

$$
\begin{aligned}
\left\|u^{\perp}\right\|_{H^{1}}^{2} & \leq \frac{C_{1}}{K_{1}}\left(\|u\|_{C}^{-\beta}+1\right)\left(\|\bar{u}\|_{H^{1}}+\|\tilde{u}\|_{H^{1}}\right) \\
& \leq C_{2}\left(\|u\|_{H^{1}}+\|u\|_{H^{1}}^{1-\beta}\right)
\end{aligned}
$$

for some constants $C_{1}, C_{2}>0$ independent of $u$. It remains to show that solutions to (17) for $0<t<1$ have an a priori bound in $H^{1}(0,2 \pi)$. We argue by contradiction and suppose that there exists a sequence $\left\{u_{n}\right\}$ of periodic functions with period $2 \pi$ and a corresponding sequence $\left\{t_{n}\right\}$ in $(0,1)$ such that $u_{n}$ is a solution to (17) with $t=t_{n}$ and $\left\|u_{n}\right\|_{H^{1}} \geq n$ for all $n$. Let $v_{n}=u_{n} /\left\|u_{n}\right\|_{H^{1}}$; then $\left\|v_{n}\right\|_{H^{1}}=1$ for all $n \in \mathbf{N}$, and by (22) we have $\left\|v_{n}^{\perp}\right\|_{H^{1}} \rightarrow 0$ as $n \rightarrow \infty$. Since $\left\|v_{n}\right\|_{H^{1}}=1$ and $\left\|P_{k} v_{n}\right\|_{H^{1}} \leq\left\|v_{n}\right\|_{H^{1}}+\left\|v_{n}^{\perp}\right\|_{H^{1}}$ for all $n \in \mathbf{N}$, we have a bounded sequence $\left\{P_{k} v_{n}\right\}$ in $H^{1}(0,2 \pi)$. For simplicity, we may assume that $v_{n}$ converges to $v$ in $H^{1}(0,2 \pi)$ for some $v \in N(L)$ with $\|v\|_{H^{1}}=1$. In particular, $v_{n} \rightarrow v$ in $C[0,2 \pi]$. Clearly, $v\left(\cdot-x_{0}\right) \in N(L)$ and $\left\|v\left(\cdot-x_{0}\right)\right\|_{H^{1}}=\|v\|_{H^{1}}$. It follows that $u_{n}(x) \rightarrow \infty$ for each $x \in \mathbf{R}$ with $v(x)>0$, and $u_{n}(x) \rightarrow$ $-\infty$ for each $x \in \mathbf{R}$ with $v(x)<0$. Since $\int_{0}^{2 \pi} u_{n}^{\prime \prime}(x) P_{k} u_{n}(x-$ $\left.x_{0}\right) d x+\int_{0}^{2 \pi} k^{2} u_{n}(x) P_{k} u_{n}\left(x-x_{0}\right) d x=0$ and $\left\|P_{k} u_{n}(\cdot)\right\|_{L^{2}}^{2}=$ $\left\|P_{k} u_{n}\left(\cdot-x_{0}\right)\right\|_{L^{2}}^{2}$, we have

$$
\begin{aligned}
& \int_{0}^{2 \pi} u_{n}^{\prime \prime}(x) P_{k} u_{n}\left(x-x_{0}\right) d x+\int_{0}^{2 \pi} k^{2} u_{n}\left(x-x_{0}\right) \\
& \cdot P_{k} u_{n}\left(x-x_{0}\right) d x=\int_{0}^{2 \pi} u_{n}^{\prime \prime}(x) \\
& \cdot P_{k} u_{n}\left(x-x_{0}\right) d x+\int_{0}^{2 \pi} k^{2} u_{n}(x) \\
& \cdot P_{k} u_{n}\left(x-x_{0}\right) d x \\
& +\int_{0}^{2 \pi} k^{2}\left[u_{n}\left(x-x_{0}\right)-u_{n}(x)\right] \\
& \cdot P_{k} u_{n}\left(x-x_{0}\right) d x \\
& =\int_{0}^{2 \pi} k^{2}\left[u_{n}\left(x-x_{0}\right)-u_{n}(x)\right] \\
& \cdot P_{k} u_{n}\left(x-x_{0}\right) d x \\
& =\int_{0}^{2 \pi} k^{2}\left[P_{k} u_{n}\left(x-x_{0}\right)-P_{k} u_{n}(x)\right] \\
& \cdot P_{k} u_{n}\left(x-x_{0}\right) d x \geq 0 .
\end{aligned}
$$

Multiplying each side of (17) by $P_{k} v_{n}\left(x-x_{0}\right)$, and then integrating them over $[0,2 \pi]$ when $u=u_{n}$ and $t=t_{n}$, we get

$$
\begin{aligned}
& t_{n} \int_{0}^{2 \pi} g\left(x, u_{n}\left(x-x_{0}\right)\right) P_{k} v_{n}\left(x-x_{0}\right) d x \\
& \quad \leq\left(1-t_{n}\right) \alpha \int_{0}^{2 \pi} u_{n}\left(x-x_{0}\right) P_{k} v_{n}\left(x-x_{0}\right) d x \\
& \quad+t_{n} \int_{0}^{2 \pi} g\left(x, u_{n}\left(x-x_{0}\right)\right) P_{k} v_{n}\left(x-x_{0}\right) d x \\
& \quad \leq t_{n} \int_{0}^{2 \pi} h(x) P_{k} v_{n}\left(x-x_{0}\right) d x
\end{aligned}
$$

By (19) and the assumption of $-1<\beta \leq 0$, we have

$$
\begin{aligned}
& g_{1}\left(x, u_{n}\left(x-x_{0}\right)\right) P_{k} v_{n}\left(x-x_{0}\right)\left\|u_{n}\right\|_{H^{1}}^{\beta} \\
& =\frac{g_{1}\left(x, u_{n}\left(x-x_{0}\right)\right)}{u_{n}\left(x-x_{0}\right)} u_{n}\left(x-x_{0}\right) P_{k} v_{n}\left(x-x_{0}\right) \\
& \cdot\left\|u_{n}\right\|_{H^{1}}^{\beta} \geq \frac{g_{1}\left(x, u_{n}\left(x-x_{0}\right)\right)}{u_{n}\left(x-x_{0}\right)} \\
& \cdot \frac{-1}{2}\left[u_{n}\left(x-x_{0}\right)-P_{k} u_{n}\left(x-x_{0}\right)\right]^{2}\left\|u_{n}\right\|_{H^{1}}^{\beta-1} \geq \frac{-1}{2} \\
& \cdot a(x)\left[u_{n}^{\perp}\left(x-x_{0}\right)\right]^{2}\left\|u_{n}\right\|_{H^{1}}^{\beta-1}
\end{aligned}
$$

for a.e. $x \in(0,2 \pi)$. Combining (22) with (25), we get that $g_{1}\left(x, u_{n}\left(x-x_{0}\right)\right) P_{k} v_{n}\left(x-x_{0}\right)\left\|u_{n}\right\|_{H^{1}}^{\beta}$ is bounded from below 
by an $L^{1}(0,2 \pi)$-function independent of $n$. By (20) and the assumption of $-1<\beta \leq 0$, we have

$$
\begin{aligned}
\left|g_{2}\left(x, u_{n}\left(x-x_{0}\right)\right) P_{k} v_{n}\left(x-x_{0}\right)\right|\left\|u_{n}\right\|_{H^{1}}^{\beta} & \\
\leq & {\left[e(x)\left|u_{n}\left(x-x_{0}\right)\right|^{-\beta}+e(x)\right]\left|P_{k} v_{n}\left(x-x_{0}\right)\right| } \\
\cdot & \left\|u_{n}\right\|_{H^{1}}^{\beta} \leq\left[e(x)\left|v_{n}\left(x-x_{0}\right)\right|^{-\beta}+e(x)\right] \\
\cdot & \left|P_{k} v_{n}\left(x-x_{0}\right)\right|
\end{aligned}
$$

for a.e. $x \in(0,2 \pi)$, In particular, $g_{2}\left(x, u_{n}(x-\right.$ $\left.\left.x_{0}\right)\right) P_{k} v_{n}\left(x-x_{0}\right)\left\|u_{n}\right\|_{H^{1}}^{\beta}$ is bounded from below by an $L^{1}(0,2 \pi)$-function independent of $n$, which implies that $g\left(x, u_{n}\left(x-x_{0}\right)\right) P_{k} v_{n}\left(x-x_{0}\right)\left\|u_{n}\right\|_{H^{1}}^{\beta}$ is also so, $\int_{v\left(x-x_{0}\right)=0} \liminf \operatorname{in}_{n \rightarrow \infty} g\left(x, u_{n}\left(x-x_{0}\right)\right) P_{k} v_{n}\left(x-x_{0}\right)\left\|u_{n}\right\|_{H^{1}}^{\beta} d x=$ 0 , and

$$
\begin{gathered}
g\left(x, u_{n}\left(x-x_{0}\right)\right) P_{k} v_{n}\left(x-x_{0}\right)\left\|u_{n}\right\|_{H^{1}}^{\beta} \\
=\frac{g\left(x, u_{n}\left(x-x_{0}\right)\right) u_{n}\left(x-x_{0}\right)}{\left|u_{n}\left(x-x_{0}\right)\right|^{1-\beta}} \\
. \frac{P_{k} v_{n}\left(x-x_{0}\right) \operatorname{sgn}\left(u_{n}\left(x-x_{0}\right)\right)}{\left|v_{n}\left(x-x_{0}\right)\right|^{\beta}}
\end{gathered}
$$

for all $n \in \mathbf{N}$ with $u_{n}\left(x-x_{0}\right) \neq 0$. Here $\operatorname{sign}(w)=1$ if $w>0$, $\operatorname{sign}(w)=0$ if $w=0$, and $\operatorname{sign}(w)=-1$ if $w<0$. Applying Fatou's lemma to the integral $\int_{0}^{2 \pi} g\left(x, u_{n}\left(x-x_{0}\right)\right) P_{k} v_{n}(x-$ $\left.x_{0}\right)\left\|u_{n}\right\|_{H^{1}}^{\beta} d x$, we have

$$
\begin{aligned}
& \int_{v\left(x-x_{0}\right)>0} g_{\beta}^{+}(x)\left|v\left(x-x_{0}\right)\right|^{1-\beta} d x+\int_{v\left(x-x_{0}\right)<0} g_{\beta}^{-}(x) \\
& \cdot\left|v\left(x-x_{0}\right)\right|^{1-\beta} d x \\
& =\int_{v\left(x-x_{0}\right)>0} \liminf _{n \rightarrow \infty} \frac{g\left(x, u_{n}\left(x-x_{0}\right)\right) u_{n}\left(x-x_{0}\right)}{\left|u_{n}\left(x-x_{0}\right)\right|^{1-\beta}} \\
& \cdot \lim _{n \rightarrow \infty} \frac{P_{k} v_{n}\left(x-x_{0}\right) \operatorname{sgn}\left(u_{n}\left(x-x_{0}\right)\right)}{\left|v_{n}\left(x-x_{0}\right)\right|^{\beta}} d x \\
& +\int_{v\left(x-x_{0}\right)<0} \liminf _{n \rightarrow \infty} \frac{g\left(x, u_{n}\left(x-x_{0}\right)\right) u_{n}\left(x-x_{0}\right)}{\left|u_{n}\left(x-x_{0}\right)\right|^{1-\beta}} \\
& \quad \cdot \lim _{n \rightarrow \infty} \frac{P_{k} v_{n}\left(x-x_{0}\right) \operatorname{sgn}\left(u_{n}\left(x-x_{0}\right)\right)}{\left|v_{n}\left(x-x_{0}\right)\right|^{\beta}} d x \\
& \quad=\int_{v\left(x-x_{0}\right)>0} \liminf _{n \rightarrow \infty} g\left(x, u_{n}\left(x-x_{0}\right)\right) P_{k} v_{n}\left(x-x_{0}\right) \\
& +\left\|u_{n}\right\|_{H^{1}}^{\beta} d x \\
& +\int_{v\left(x-x_{0}\right)<0} \liminf _{n \rightarrow \infty} g\left(x, u_{n}\left(x-x_{0}\right)\right) P_{k} v_{n}\left(x-x_{0}\right)
\end{aligned}
$$

$$
\begin{aligned}
& \cdot\left\|u_{n}\right\|_{H^{1}}^{\beta} d x \\
& =\int_{v\left(x-x_{0}\right)>0} \liminf _{n \rightarrow \infty} g\left(x, u_{n}\left(x-x_{0}\right)\right) P_{k} v_{n}\left(x-x_{0}\right) \\
& \cdot\left\|u_{n}\right\|_{H^{1}}^{\beta} d x \\
& +\int_{v\left(x-x_{0}\right)<0} \liminf _{n \rightarrow \infty} g\left(x, u_{n}\left(x-x_{0}\right)\right) P_{k} v_{n}\left(x-x_{0}\right) \\
& \cdot\left\|u_{n}\right\|_{H^{1}}^{\beta} d x+\int_{v\left(x-x_{0}\right)=0} \lim _{n \rightarrow \infty} g\left(x, u_{n}\left(x-x_{0}\right)\right) \\
& \cdot P_{k} v_{n}\left(x-x_{0}\right)\left\|u_{n}\right\|_{H^{1}}^{\beta} d x \\
& =\int_{0}^{2 \pi} \lim _{n \rightarrow \infty} g\left(x, u_{n}\left(x-x_{0}\right)\right) P_{k} v_{n}\left(x-x_{0}\right) \\
& \cdot\left\|u_{n}\right\|_{H^{1}}^{\beta} d x \leq \liminf _{n \rightarrow \infty} \int_{0}^{2 \pi} g\left(x, u_{n}\left(x-x_{0}\right)\right) \\
& \cdot P_{k} v_{n}\left(x-x_{0}\right)\left\|u_{n}\right\|_{H^{1}}^{\beta} d x \leq(1+\operatorname{sign}(\beta)) \\
& \cdot \int_{0}^{2 \pi} h(x) v\left(x-x_{0}\right) d x,
\end{aligned}
$$

which is a contradiction when either (8) with $-1<\beta<0$ or (9) with $\beta=0$ is satisfied. Hence, the proof of this theorem is complete.

By slightly modifying the proof of Theorem 3, we can apply Lemma 2 to obtain an existence theorem to (2) when condition $(H)$ is replaced by $(G)$ and either (8) with $-1<\beta<$ 0 or (9) with $\beta=0$ is satisfied, which has been established in [20] for the case $x_{0}=0$ when (9) with $\beta=0$ is satisfied and in [9] for the case $x_{0}=0$ when (8) with $\beta=-1$ is satisfied.

Theorem 4. Let $k \in \mathbf{N}$ and $g:(0,2 \pi) \times \mathbf{R} \rightarrow \mathbf{R}$ be a Caratheodory function satisfying $(G)$. Then for each $h \in$ $L^{1}(0,2 \pi)$ problem (2) has a solution $u$, provided that either (8) with $-1<\beta<0$ or (9) with $\beta=0$ holds.

\section{Conflicts of Interest}

There are no conflicts of interest involved.

\section{References}

[1] P. Drábek, "Landesman-lazer condition for nonlinear problem with jumping nonlinearity," Journal of Differential Equations, vol. 85, no. 1, pp. 186-199, 1990.

[2] P. Drábek and S. Invernizzi, "On the periodic BVP for the forced duffing equation with jumping nonlinearity," Nonlinear Analysis: Theory, Methods \& Applications, vol. 10, no. 7, pp. 643650, 1986.

[3] J.-P. Gossez and P. Omari, "Nonresonance with respect to the Fucik spectrum for periodic solutions of second order ordinary differential equations," Nonlinear Analysis: Theory, Methods \& Applications, vol. 14, no. 12, pp. 1079-1104, 1990. 
[4] C. P. Gupta, J. J. Nieto, and L. Sanchez, "Periodic solutions of some lienard and duffing equations," Journal of Mathematical Analysis and Applications, vol. 140, no. 1, pp. 67-82, 1989.

[5] C. P. Gupta and J. Mawhin, "Asymptotic conditions at the two first eigenvalues for the periodic solutions of lineard differential equations and an inequality of E. Schmidt," Zeitschrift Für Analysis Und Ihre Anwendungen, vol. 3, no. 1, pp. 33-42, 1984.

[6] C. P. Gupta, "Solvability of a forced autonomous duffing's equation with boundary conditions in the presence of damping," Applications of Mathematics, vol. 38, no. 3, pp. 195-203, 1993.

[7] R. Iannacci and M. N. Nkashama, "Nonlinear two-point boundary value problems at resonance without landesmanlazer condition," Proceedings of the American Mathematical Society, vol. 106, no. 4, pp. 943-952, 1989.

[8] C.-C. Kuo, "Periodic solutions of a two-point boundary value problem at resonance," Osaka Journal of Mathematics, vol. 37, no. 2, pp. 345-353, 2000.

[9] C.-C. Kuo, "On the solvability of semilinear differential equations at resonance," Proceedings of the Edinburgh Mathematical Society, vol. 43, no. 1, pp. 103-112, 2000.

[10] M. Martelli and J. D. Schuur, "Periodic solutions of linear type second order ordinary differential equations," Tohoku Mathematical Journal, vol. 32, pp. 337-351, 1983.

[11] J. Mawhin and J. Ward, "Periodic solutions of some forced lineard differential equations at resonance," Archiv der Mathematik, vol. 41, no. 4, pp. 337-351, 1983.

[12] J. Mawhin and J. R. Ward, "Nonuniform nonresonance conditions at the two first eigenvalues for periodic solutions of forced lineard and duffing equations," Rocky Mountain Journal of Mathematics, vol. 12, no. 4, pp. 643-654, 1982.

[13] J. R. Ward Jr., "Periodic solutions for systems of second order differential equations," Journal of Mathematical Analysis and Applications, vol. 81, no. 1, pp. 92-98, 1981.

[14] R. Iannacci and M. N. Nkashama, "Nonresonance conditions for periodic solutions of lineard and duffing equations with delay," Annales de la Société scientifique de Bruxelles Série I, vol. 99, no. 1, pp. 29-43, 1985.

[15] R. Iannacci and M. N. Nkashama, "On periodic solutions of forced second order differential equations with a deviating argument," in Lecture Notes in Mathematics, vol. 1151, pp. 224232, Springer, Berlin, Germany, 1985.

[16] E. De Pascale and R. Iannacci, "Periodic solutions of generalized lineard equations with delay," in Lecture Notes in Mathematics, vol. 1017, pp. 148-156, Springer, Berlin, Germany, 1983.

[17] R. Kannan and R. Ortega, "Periodic solutions of pendulum-type equations," Journal of Differential Equations, vol. 59, no. 1, pp. 123-144, 1985.

[18] K. Deimling, Nonlinear Functional Analysis, Springer, New York, NY, USA, 1985.

[19] J. Mawhin, Topological Degree Methods in Nonlinear Boundary Value Problems, vol. 40 of CBMS Regional Conference Series in Mathematics, American Mathematical Society, Providence, RI, USA, 1979.

[20] R. Iannacci and M. N. Nkashama, "Nonlinear boundary value problems at resonance," Nonlinear Analysis. Theory, Methods \& Applications, vol. 11, no. 4, pp. 455-473, 1987. 


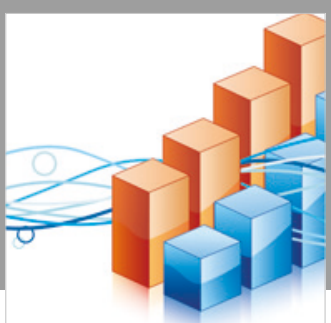

Advances in

Operations Research

\section{-n-m}
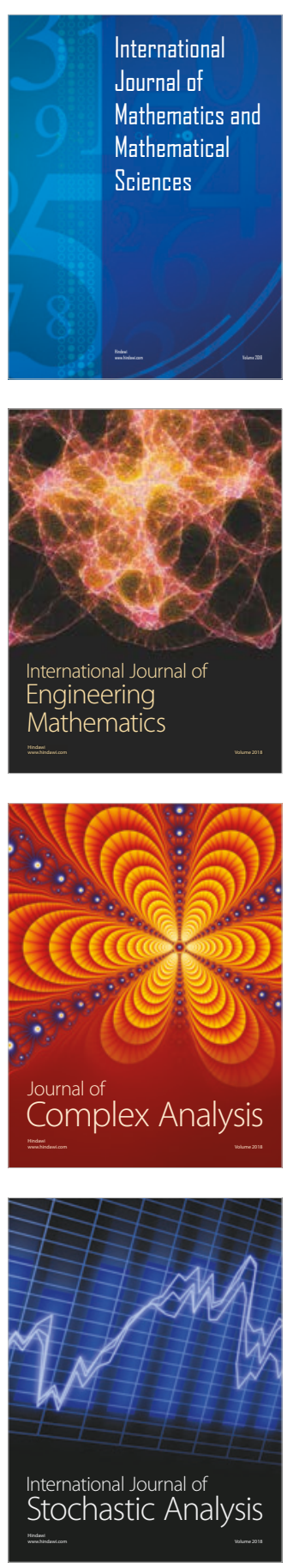
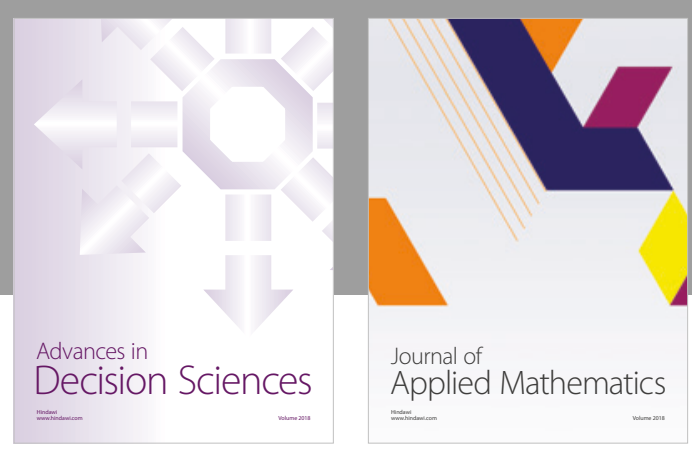

Journal of

Applied Mathematics
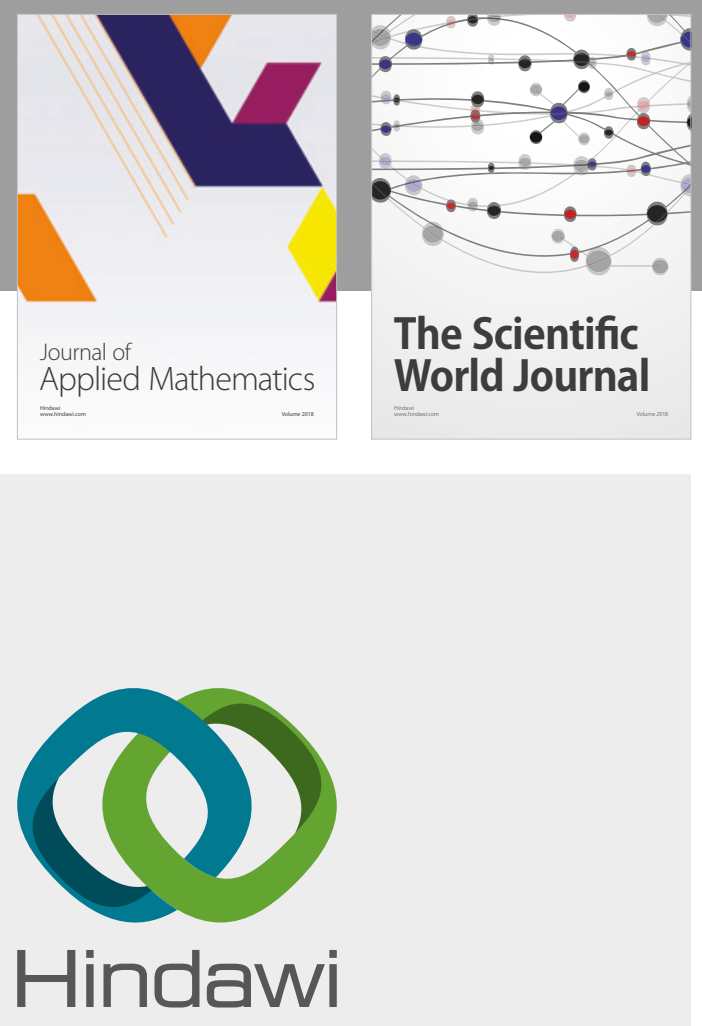

Submit your manuscripts at

www.hindawi.com

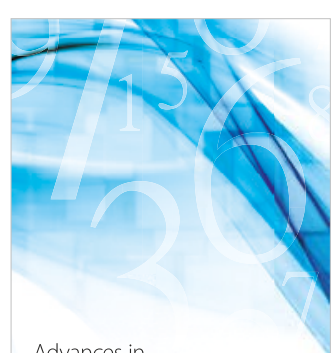

Advances in
Numerical Analysis
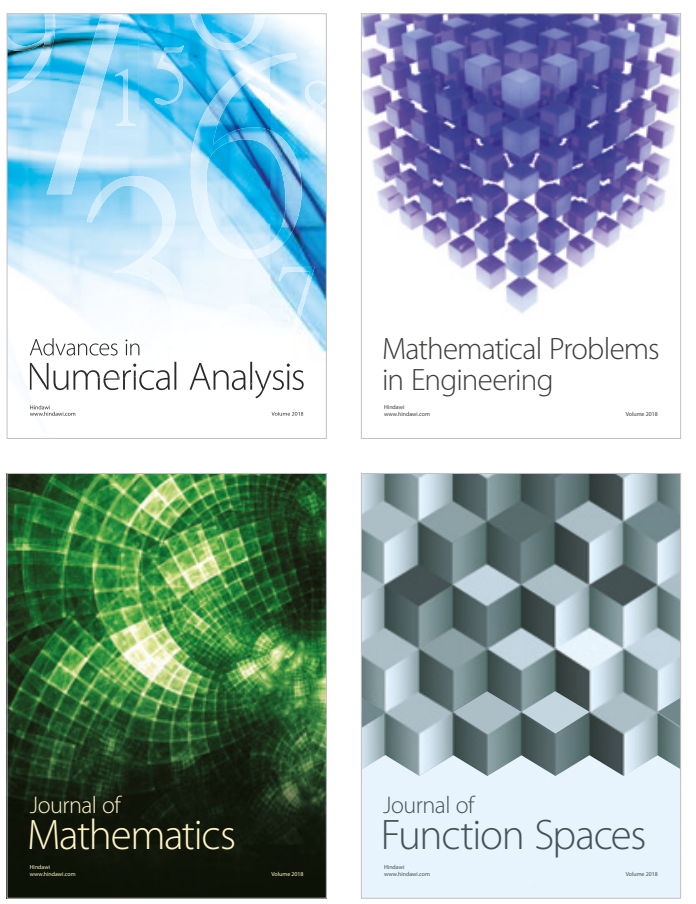

Mathematical Problems in Engineering

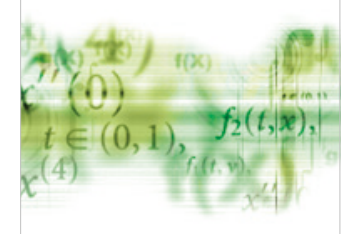

International Journal of

Differential Equations

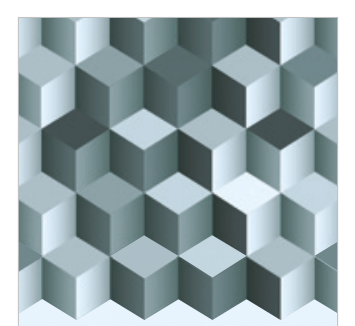

Journal of

Function Spaces

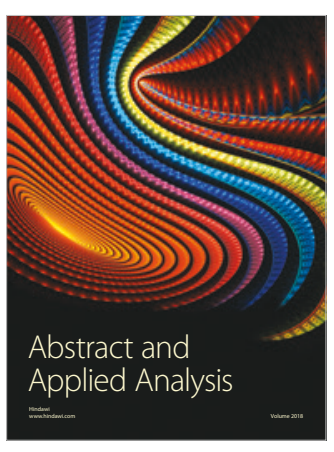

The Scientific

World Journal

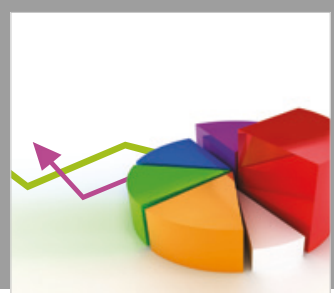

Journal of

Probability and Statistics
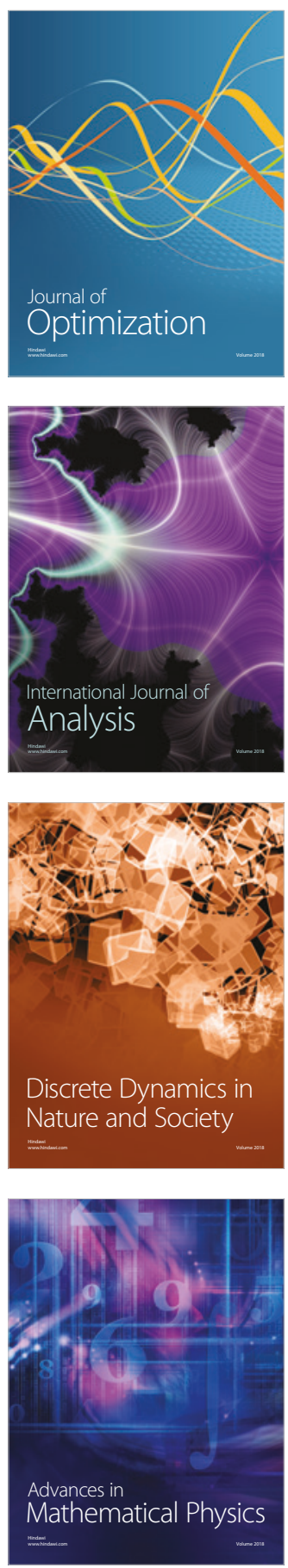